\title{
MOSEM in Teaching Sciences \\ Processes and Results from Media Studies
}

\author{
Lucía Amorós
}

University of Murcia, Spain

DOI: https://doi.org/10.7358/ijtl-2017-006-amo

amoros@um.es

ABSTRACT - MOSEM offers participating schools and teachers a collection of thought-provoking tabletop physics experiments. Digital and printed support materials use text, video and animation to raise the user's curiosity. There are three questions to resolve in this paper. Firstly, I will focus on the pedagogical backgrounds of MOSEM. Secondly, I will explain the assessment doing. And, finally, I will offer my point of view and explain why MOSEM is important to me.

\section{INTRODUCTION}

Physics On Stage Conference in the early XXI century in Geneva, told us there was a crisis in physics education and a need for revitalization of physics teaching. They explained physics education in Europe was facing a crisis regarding lack of recruitment. Then, the large numbers of physics teachers would end their active careers.

In that time, it is considered this had affected the potential for technology progress and the development of society and vice versa (MOSEM, 2011). Nowadays I know that both floors of CERN's main building were for a few days a lively and colourful physics teaching fair (CERN, 2000).

Delegates of the festival and passers-by played with the Slovakian 'schola Ludus' hand-made display, a group of Portuguese students demonstrated chaos theory with a water wheel, Poland decorated their stand with gingerbread hearts reading ' $E=$ mc2', and Austria took a walk of the fair with spider as robots which were steered via the internet by their colleagues in Vienna. Luckily, three years later I practiced by my own this kind of telekinesis in DECONISM, at the McLuhan Program in Culture and Technology of the University of Toronto.

International Journal of Transmedia Literacy - 3 - December 2017

http: //www.ledonline.it/transmedialiteracy - Online ISSN 2465-2261 - Print ISSN 2465-227X 
In this sense resources were made by Superlab at NTNU and Simplicatus (Norway) since 1998 to 2001. Then the SUPERCOMET (SC and after SC2) project aimed to contribute to change this unfortunate trend by providing educational materials that are challenging, interesting, and fun for both pupils and teachers.

This project was the real background of MOSEM (Figure 1) and the bases to start as an educator, an incredible way looking for not only economic resources as possible as I could, but theory and practice in the methodology included. It means, combining modern pedagogical methods as collaborative learning and student-centred problem solving with computer simulations.

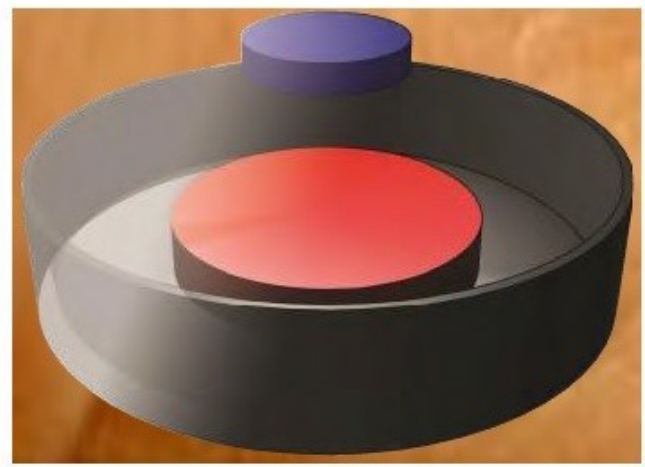

Figure 1. A superconductor (big red circle) with liquid nitrogen made that a magnet levitates (little blue circle). Quantum Levitation.

SUPERCOMET 2 guaranteed the aims to connect the intriguing phenomenon of superconductivity with the curricula subjects of upper secondary schools in several countries. An accompanying teacher's guide and inservice teacher training seminar ensured that tools and methods were successfully implemented. Most of these results were published in Engstrøm et al. (2007), Fernández et al. (2010), Martínez et al. (2010) and Zamarro and Amorós (2011).

International Journal of Transmedia Literacy - 3 - December 2017

http: //www.ledonline.it/transmedialiteracy - Online ISSN 2465-2261 - Print ISSN 2465-227X 


\section{ACTIONS AS EDUCATIONAL TECHNOLOGY'S EXPERT}

People and politicians complain that school is getting easier. But MOSEM, a 10-year- old project, decided to show it for itself. Chiefly it spends more than $€ 1.000 .000$ in research for European Secondary schools. Nowadays MOSEM works in collaboration with 28 countries around the world as you can see on the website http://mosem.eul.

Educational Technology's expert (ETs expert at this time) on MOSEM is relevant if we will remember that physics' contents in teaching sciences are part of the curriculum as part of the maturity period of student. As soon as possible they will be citizens with voice and vote. For that reason, although this is a description which considers job of the ETs experts around of pedagogical accountability, I will show the pedagogic labour that I have done for these years too. From my point of view neither mathematical nor physical can do it. It is a pity.

The next step of course, it is highlighting that job is just part of a complete pedagogical work because other partners have been leaders in other moments or have pushed assessment in a specific way. For instance, the Ostravská Univerzita (Czech Republic) or the Institute of Education in the University of London (UK).

In essence, a partial picture has been drawn in the Figure 2. The picture is divided in 5 columns. The first column YEAR notes the date between MOSEM projects, ETs actions, places of work and the kind of budget as well. The second column PROJECT/email tells you the name of projects living in paradox. The third column, ACTIONS, describes activities, for instance assessment, teaching, observation, testing, collaborative work, special needs, image in cinema and video games. While, the ETs EXPERT column tells about places of work according with MOSEM aims and the European Union. Finally, the column BUDGET gives you information about public or private financing and direct budget for $\mathrm{R}+\mathrm{D}+\mathrm{I}$. I suggest you to look at figure 2 . As you can see, there are two best moments living in paradox, please see PROJECT/ email and ETs EXPERT columns. 


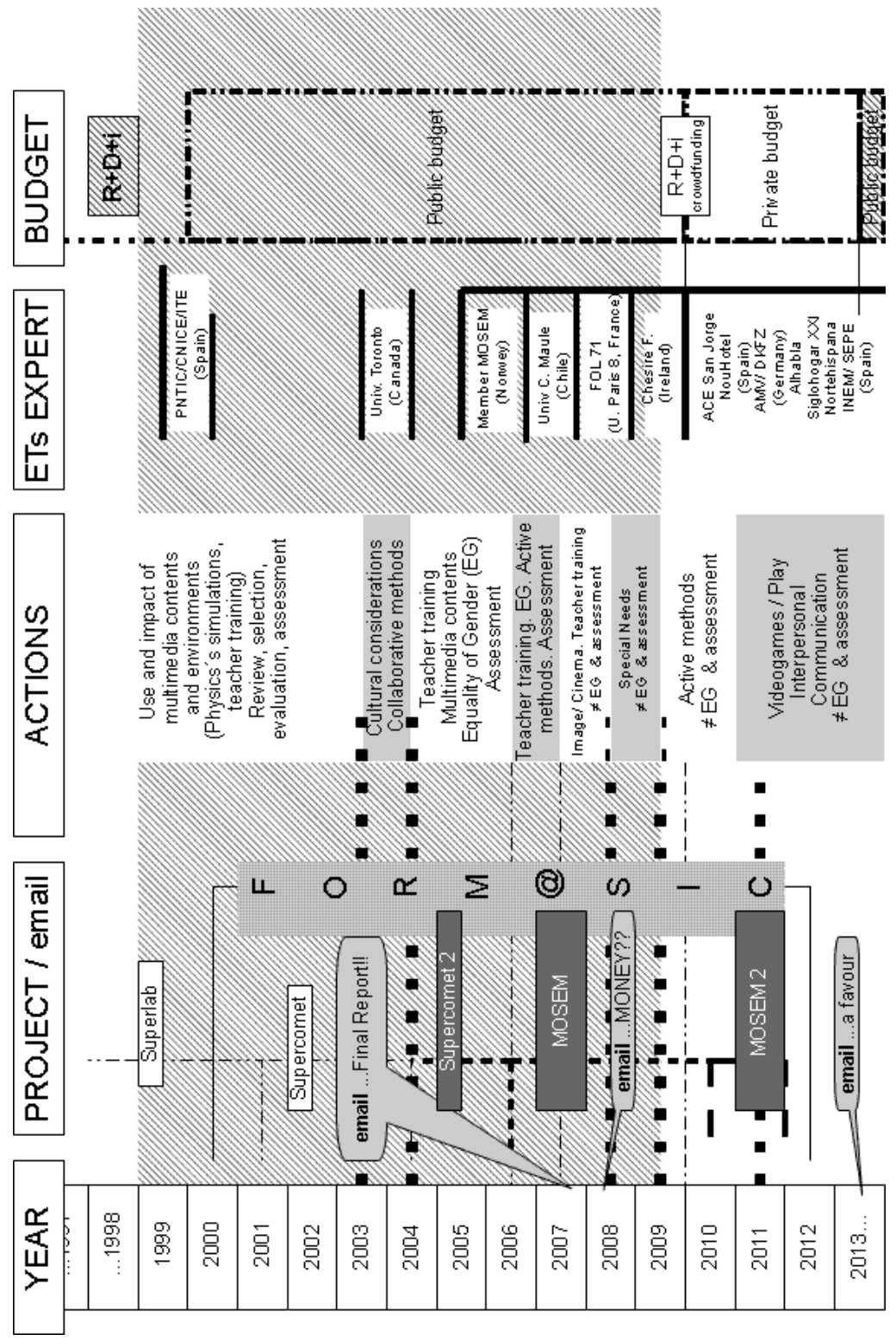

Figure 2. MOSEM. Processes by date, name of the projects, actions, places and budget

International Journal of Transmedia Literacy - 3 - December 2017

http: //www.ledonline.it/transmedialiteracy - Online ISSN 2465-2261 - Print ISSN 2465-227X 
On the one hand, my best moment in my research life with MOSEM was when I left my university. That is to say Universidad de Murcia counted on me as member of MOSEM (SUPERCOMET at that time) while my mind said, are not you pleased about MOSEM? Why are not you more active? And then I thought, "I am ... but I will show you later". At that time, I had signed an agreement, but I had some questions to resolve and lots of statistics to publish according with aims to improving teaching sciences. The sequel of my research has been drawn in the ETs EXPERT column.

In turn, I thought that the scientific manager shares this idea because he was still giving me information. By the way I had to check my email on and on. At that time, emails came every week or every month. And then what I had to do was to translate MOSEM instructions, finishing reports as well as writing on the terms of multimedia, methodology and media assessment (Figure 3). To be honest, I could not believe it! Sometimes it was really difficult. In other words, MOSEM was (is) very demanding - I had to do my best every time - but it was very interesting, anyway.

On the other hand, my second-best moment living in paradox ${ }^{1}$ (email 05/03/2008) was when MOSEM asked me: "How much could you do for 2.000 Euro? For 5.000 Euro? For 10.000 Euro?". I have to confess that is a suitable question and its answer changed the kind of assessment after all because I could not answer.

So, I asked myself again, "what exactly did I have to do?" I decided to pick up economic evidences of my research and describe them in next reports (MOSEM and MOSEM2). Then, I had to forget questionnaires and other kinds of interviews about topics such as equality of gender, inclusion, pedagogical criteria to digital simulations and so on. I will answer about it in next pages.

Generally speaking, Leonardo Da Vinci Programme (LdV) works in financing of research projects. This is necessary for a reliable research, because a project will need financing if we work in a formal way. However, Form@sic(@lis Programme, Alliance for the Information Society) is an example of that, but at the reverse (Figure 2, column YEAR and PROJECT).

This programme for cooperation with Latin America was launched by the European Commission and it never arrived to Brussels, so budget disappeared over a virtual dream, ever real. The aims of Form@sic are digital contents with pedagogical quality, web telling us advances and finally a broadcasting by satellite of these contents.

\footnotetext{
${ }^{1}$ Ars Electronica 2005, Linz (Austria)
} 


\begin{tabular}{|c|c|c|}
\hline Date/ Fecha & From/De & Subject/ Asunto \\
\hline $10 / 09 / 06$ & SUPERCOMET 2 Project & SC2: Procedures for reimbursem \\
\hline $10 / 09 / 06$ & SUPERCOMET 2 Project & SC2: Procedures for reimbursem \\
\hline $10 / 09 / 06$ & SUPERCOMET 2 Project & RE: SC2: Procedures for reimbursem \\
\hline $11 / 09 / 06$ & SUPERCOMET 2 Project & SC2: Bank transfer - P17 Murcia \\
\hline $11 / 09 / 06$ & SUPERCOMET 2 Project & SC2: Intranet news item - Bank $t$ \\
\hline $04 / 10 / 06$ & SUPERCOMET 2 Project & SC2: Intranet news item - Project ph \\
\hline $04 / 10 / 06$ & SUPERCOMET 2 Project & SC2: Intranet news item - New Help \\
\hline $04 / 10 / 06$ & SUPERCOMET 2 Project & Re: SC2: Intranet news item - Pri \\
\hline $21 / 10 / 06$ & SUPERCOMET 2 Project & SC2: Email addresses to project part \\
\hline $25 / 10 / 06$ & SUPERCOMET 2 Project & SC2: Budget revision for Operatir \\
\hline $23 / 12 / 06$ & SUPERCOMET 2 Project & SC2: New version of Computer Appli \\
\hline $23 / 12 / 06$ & SUPERCOMET 2 Project & SC2: Project Fact Sheet \\
\hline $20 / 01 / 07$ & SUPERCOMET 2 Project & SC2: Corrected version of Compu \\
\hline $20 / 01 / 07$ & SUPERCOMET 2 Project & SC2: Text updates for Computer \\
\hline $26 / 01 / 07$ & SUPERCOMET 2 Project & SC2: Computer Application - post \\
\hline $12 / 06 / 07$ & SUPERCOMET 2 Project & SC2: Status for project and comp \\
\hline $12 / 06 / 07$ & SUPERCOMET 2 Project & SC2: LdV Evaluation survey \\
\hline $22 / 06 / 07$ & SUPERCOMET 2 Project & SC2: Call for tenders for compute \\
\hline $27 / 10 / 07$ & webmaster@supercomet.no & SUPERCOMET 2 user guide \\
\hline $22 / 11 / 07$ & webmaster@supercomet.no & SUPERCOMET 2 Information \& ne \\
\hline
\end{tabular}

Figure 3. MOSEM emails from SUPERCOMET 2.

(lamoros@um.es,From:Supercomet)

All of that according with quality, equity, and social inclusion with the focus on internationalize the project. In this sense, MOSEM appeared in the best moment making a strong link between MOSEM aims and Form@sic aims.

\section{ECONOMIC ASSESSMENT}

In the first part, I described where I had been as an educator and as an educational technology expert. From my point of view, one of the hardest things for any scientist is to know when to retire because... do you retire 
when you are at your economic 'peak' or do you wait until your coach tells you that it is time to go?

MOSEM is a classic example yet, but sadly, I think for most scientist this project is the exception. Moreover, when you hear the final whistle, perhaps for scientist there is an extra trauma - the loss of status, the loss of recognition, and the loss of the glamour. That is the hardest part. Maybe not so much time ago, the typical-extended project of research was 'wide'. It usually consisted of two or three scientific generation in the same field with science's children who could be called young scientists, in each scientific nuclear family.

After all, scientists had lots of scientific aunts and uncles but often they did not meet their scientific grandparents. Nowadays, in the case of MOSEM, ETs expert must look for financing. For this reason, its scientific family is 'long and thin'. It is long because it is necessary to keep in contact with lots of friends, enterprises, and institutions. It is thin because after a short job with them this relation is finished when collaboration, contract or agreement is not $\mathrm{R}+\mathrm{D}+\mathrm{I}$. As a result, curiously, simultaneously and chiefly in this process you remember who your scientific family is, including your great-grand parents. They will push yourself when you are in need.

\subsection{Method}

Beyond our family as a result the economic assessment shows how to continue working. Statistics were done by an analysis of content, according to Krippendorff (1980), Pérez (1984), Prendes (1994) and Rodríguez et al. (1996) and with Google Docs, with a previous practice in Systat and works such as Sánchez et al. (1984) and Ato and López (1994). Considering all the details, the category of analysis is COST (expense).

Codes (Table 1) are useful as they exhibit practical results, they are clear because they are defined simply detailing their values. They are right to follow similar patterns to favour the interpretation while accompanied by translation with an official document (LdV - Leonardo Da Vinci Programmes) and to finish they are excluded from themselves because they do not collect redundant results. In addition, the code DATE has 20 values, the code COMPANY has 26 values, the code CONCEPT has 5 values, the code COSTS has 6 values and the code FILE has 372 values.

International Journal of Transmedia Literacy - 3 - December 2017

http: //www.ledonline.it/transmedialiteracy - Online ISSN 2465-2261 - Print ISSN 2465-227X 
Table 1. Codes from category COST to operative definition.Form@sic. Annex 13

\begin{tabular}{|c|c|}
\hline Category & Operative Definition \\
\hline COST & Costs in euros \\
\hline \multicolumn{2}{|c|}{ Codes } \\
\hline DATE & Semester per year \\
\hline COMPANY & $\begin{array}{l}\text { Enterprise, like organizational unit } \\
\text { dedicated to industrial, commercial } \\
\text { or informational services, training } \\
\text { and / or social. Place in which to } \\
\text { perform these activities. Attempt or } \\
\text { plan to do something. Action or task } \\
\text { that involves difficulty and the ex- } \\
\text { ecution decision and effort. }\end{array}$ \\
\hline CONCEPT & Description of the cause of a cost \\
\hline COSTS & Costs in euros \\
\hline FILE & $\mathrm{ua}=$ Unit of analysis \\
\hline
\end{tabular}

Finally, with attention in this economic assessment, I have to consider three periods of times incidentally divided every year in two parts. So, the first one is from 2003 until 2005. The second one is between 2006 and 2010. The last period of time includes 2011 and the first half of 2012 .

\subsection{Results}

In response to period 1 (Figure 4) total cost is $€ 2.236$ between 2003 and 2005. This will be a minor cost if we compare it in next periods as I will discuss below. Considering the first period in particular, it is noted that the first half of 2003 has a spending $4.8 \%$ of the total, with $€ 53$ (12003). There is no expense recorded for the second half of 2003 and the first half of 2004. Finally, the cost on the second half was $76.5 \%$ of the total cost, with $€ 848$ in 2004 . While, it was spent $€ 202$ in the first half $(18.2 \%)$ and $€ 5$ in the second $(0.5 \%)$ in 2005 . 


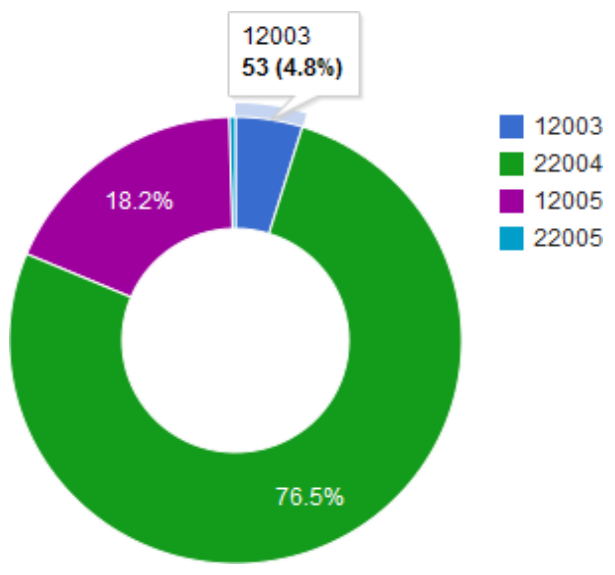

Figure 4.Form@sic-MOSEM. Category COST. First period. 3 years. Percentages.

The high cost was in the second semester 2004 (green, 22004).

In contrast, $€ 30.565$ were spent from 2006 to 2010 . Here all semesters have expenses as you can see in figure 5. However, in the first half 2007, followed by the second half of this year, there is a higher cost compared with other semesters and years. Only in 2007 was spent $€ 16.969$, of which $€$ 13.745 belong to the first half $(45 \%)$ and $€ 3.224$ to the second half $(10.5 \%)$.

However, 2008-year has very low values, with only $€ 15$ spent in the first half and $€ 2.250$ on the second semester. According to Table 2 and Figure 5, during the year 2006 it had spent $€ 1.957$ euros $(6.4 \%$ of total costs) in the first semester and $€ 2.383(7.8 \%)$ in the second. In 2009 there is a $3.5 \%$ of total costs in the first half which means $€ 1.073$. Similarly, $€$ 1.035 were spent in the second, which represents a $3.4 \%$ of total costs in this period. Finally, 2010-year will be high in costs if we compare it with last year, especially visible in the first half of the year with a $10.6 \%$ of total costs $(€ 3.252)$ and a $5.3 \%$ of total costs $(€ 1.631)$ in the second half of the year. 


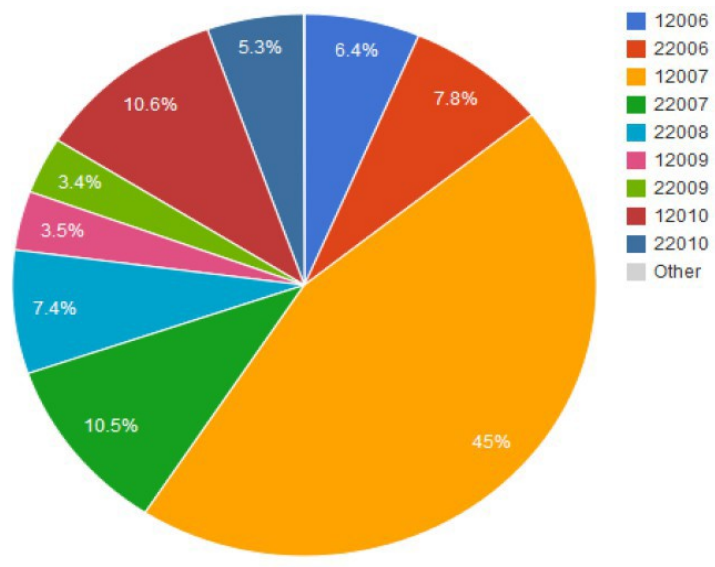

Figure 6. Form@sic-MOSEM. Category COST. 2nd period. 5 years. Percentages. The high cost was in the 1st semester of 2007 (orange, 12007).

Table 2. Costs since 2006 to 2010. Form@sic-MOSEM. Category COST. 2nd period. 5 years. Semester $x$ Euros.

$\begin{array}{cccc}\text { Year } & \text { Semester } & \text { Code } & \text { Cost } \\ 2006 & 1 & 12006 & € 1957 \\ & 2 & 22006 & € 2383 \\ 2007 & 1 & 12007 & € 13745 \\ & 2 & 22007 & € 3224 \\ 2008 & 1 & 12008 & € 15 \\ & 2 & 22008 & € 2250 \\ 2009 & 1 & 12009 & € 1073 \\ & 2 & 22009 & € 1035 \\ 2010 & 1 & 12010 & € 3252 \\ & 2 & 2210 & € 1631\end{array}$

Considering the period 3 (Figure 6) the total cost is $€ 3.501$ between 2011and 2012. But observe that in 2012 just concerns the first semester. The majority of Euros are available in the second semester 2011, with

International Journal of Transmedia Literacy - 3 - December 2017 http: //www.ledonline.it/transmedialiteracy - Online ISSN 2465-2261 - Print ISSN 2465-227X 
$€ 1.760$ spent. However, in the first half of 2011 was spent $€ 1.388$ (36.6\%) while in the first half of 2012 was spent $€ 353$ (10.1\% of the total spent in this period).

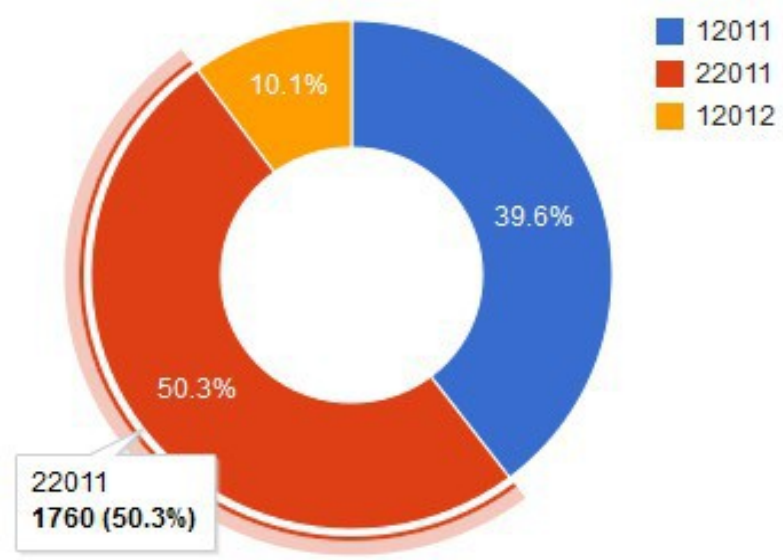

Figure6.Form@sic-MOSEM. Category COST.3rd period. 2 years. Percentages. The high cost was in the 2nd semester of 2011 (red, 22017).

\section{WHY MOSEM IS IMPORTANT FOR ME? SOME THOUGHTS}

Perhaps scientist just can not stand life without the 'high' of professional research. But I think scientific family is changing shape. Coupled with this ET's expert case, 26 companies had collaborated in MOSEM. According with European Union's aims, ET work needs more than $€ 36.000$ in this case. Moreover, if I considered time, I could need 10 years to do the same process. About results, it has been coded 372 units of analysis to complete just part of the body of Educational Technology in MOSEM.

In this process I have discovered that for an ET expert is so complicate to speak about tasks and money because all depend on the environment and the necessities of it. The results show with evidences as the economic assessment as the question

"How much could you do for 2.000 Euro? For 5.000 Euro? For 10.000 Euro?" is inappropriate to an educator in the field of research. A fun answer could be making a mathematical division between $€ 36.302$

International Journal of Transmedia Literacy - 3 - December 2017

http: //www.ledonline.it/transmedialiteracy - Online ISSN 2465-2261 - Print ISSN 2465-227X 
(some ET costs in MOSEM) and 10 years (time to develop MOSEM). I can answer $€ 3.630$ every year, but obviously sometimes it will be absolutely too much and sometimes it will be extremely too little.

In addition, cultural considerations are very important too and educator not always is the same person. In other words, ET expert in MOSEM have been scholar, $\mathrm{PhD}$, teacher assistant, curricula advisor, unemployed, pupil, lecturer, volunteer, teacher, unemployed again, entertainer, nanny, telemarketer, insurance agent and unemployed again and again. But there is something incredibly true, after losing any positions at the age of $37 \mathrm{I}$ recognize there will never be anything I do that will fulfil me as much as research does.

Finally, a double paradox, that I explained before, concludes that the MOSEM link with the ETs expert is longer than the biggest professional contract or agreement. Any enterprise works just in time, however researching not at all. ETs expert is an educator, anyway.

Educator is sometimes shy but sometimes talkative, sometimes clever but sometimes not so clever, sometimes insecure but sometimes self-confident, sometimes untidy but patient, honest, unselfish, reliable, hard-working even sensible, not sensitive. In addition, educator may be bossy, competitive, jealous even manipulative, but we are always independent, charming, sociable and affectionate. The union between this scientific and MOSEM is just education. For this reason, educator must work in an open environment.

To conclude, the scientific family groups of the future will be 'long and thin'. I tell you because I had lots of professional both fathers and mothers (bosses or directors). I worked with younger than 4 and older than 80 at the same time. Moreover, I evaluated, and I was evaluated by others. After all, MOSEM promotes lifelong learning in physics and pedagogy for science teachers who will know the most important aspects of nature. Then, we will meet our scientific grandparents and even their scientific grandparents because they will remember us who we are forever.

\section{Acknowledgement}

Leonardo da Vinci Programme, MECESUP 0307 and Cheshire Ireland Foundation Cheshire Ireland Foundation. 


\section{REFERENCES}

Ato, Garcia, Manuel and Juan José Garcia Lopez. 1994. Fundamentos de estadística con SYSTAT. Madrid: RA- MA.

CERN. 2000. Physics on Stage, Physics Teaching Fair. http://physicsonstage. web.cern.ch/physicsonstage/Fair.html. Last access June 5, 2013.

Engstrøm, Vegard, Heimo Latal, Leopold Mathelitsch and Gerhard Rath, eds.. 2007. Guí del professor. SUPERCOMET. Superconductivity Multimedia Educational Tool. Fase 2. Last access March 11, 2012. http://www. fisica.uniud.it /mosem/PDF/SC2_teacher_guide_200GR.pdf. Løvenstad: Simplicatus.

Fernández, Ma. Luisa, Miguel Cañizares, Lucía Amorós and José Miguel. 2010. "Conducción eléctrica: una experiencia considerando imagen y trabajo colaborativo en la enseñanza”. Latin-American Journal of Physics Education 4 (1), 109-117. http://www.lajpe.org/index_jan10.html. Last access February 7,2010$)$.

Krippendorf, Klaus. (1990) 1980. Metodología del análisis de contenido. Teoría y práctica. Barcelona: Paidos.

Martínez, Francisco, Luisa Ma. Fernández, Lucía Amorós, Francisco Esquembre and José Zamarro. 2010. "Teacher Guide and Seminar: Experience in Physics Education”. Latin-American Journal of Physics Education, 4 (1), 174-180. Last access December 15, 2010. http://www lajpe.org/index_jan10.html.

MOSEM. (2011). SUPERCOMET Project. Article/Category 'Projects'. http:// mosem.eu /projects/supercomet. Last access June 5, 2013.

Pérez Serrano and María Gloria. 1984. El análisis de contenido de la prensa. La imagen de la Universidad a Distancia. Madrid: UNED.

Prendes Espinosa, María Paz. 1994. La imagen didáctica: Análisis descriptivo y evaluativo. Tesis doctoral. Universidad de Murcia. Inedita.

Rodríguez Gómez, Gregorio, Javier Gil Flores, and Eduardo García Jiménez. 1996. Metodología de la investigación cualitativa. Malaga: Aljibe.

Sánchez, Meca Julio, Manuel Garcia Ato, Pina José Antonio López and Nicolas Antonio Pablo Velandrino. 1989. Estadística exploratoria y confirmatoria con el paquete estadístico SYSTAT. Murcia: Servicio de Publicaciones de la Universidad de Murcia.

Zamarro, José and Lucía Amorós, eds. 2011. Las nuevas tecnologías en la enseñanza de las ciencias. Propuestas prácticas para educación secundaria. Alcalá de Guadaíra (Sevilla): MAD-Eduforma. 